\title{
HISTORIA DE UNA PARROQUIA EN TIEMPOS DE LA DICTADURA MILITAR: NUESTRA SEÑORA DE ANDACOLLO Y EL RENACIMIENTO RELIGIOSO. SAN JUAN (ARGENTINA), 1976-1983
}

\section{Carlos Moreno Fabaro y Nelson Guillermo Elizondo UNIVERSIDAD NACIONAL DE SAN JUAN. ARgENTINA}

\begin{abstract}
RESUMEN: En la Argentina, durante la última dictadura militar, en algunas comunidades parroquiales se produjo un verdadero renacimiento religioso. Esta realidad fue la que se vivió en la provincia de San Juan, en la localidad de Rawson-Villa Krause, donde se ubica la parroquia de Nuestra Señora del Rosario de Andacollo que entre 1975 y 1984 se transformó en un verdadero centro aglutinador de fieles. Fueron muchos los niños, jóvenes y adultos que encontraron un espacio mágico en el que pudieron expresarse con libertad en momentos en que los movimientos de masas estaban prohibidos.
\end{abstract}

PALABRAS CLAVE: Renacimiento, religiosidad, dictadura, espacio mágico, creyentes.

\section{HISTORY OF A PARISH IN TIMES OF MILITARY DICTATORSHIP. OUR LADY OF ANDACOLLO AND RELIGIOUS REVIVAL. SAN JUAN, ARGENTINA, 1976-1983.}

SUMMARY: In Argentina, during the last military dictatorship, in some parishes there was a genuine religious revival. This actually was the one that lived in the province of San Juan, in the town of Rawson-Villa Krause, site of the parish of Our Lady of the Rosary of Andacollo, that between 1975 and 1984 became a real center of faithful. There were many children, youth and adults who found a magical space in which they could express themselves freely at a time when mass movements were banned.

KEY WORDS: Renaissance, religious, magical space, dictatorship, believers 


\section{PRESENTACIÓN}

En el centro de la República Argentina se localiza la provincia de San Juan, abarcando una superficie de $89.651 \mathrm{~km}^{2}$, con una figura singular se extiende de norte a sur entre los paralelos $28^{\circ}$ y $32^{\circ}$ de latitud sur, de oeste a este entre los $66^{\circ}$ y $70^{\circ}$ de longitud oeste.

La provincia se encuentra organizada en diecinueve municipios (ayuntamientos) que gobiernan los departamentos, estos últimos son distritos que tienen bien definidos sus límites y dentro de ellos existen agrupamientos poblacionales que se definen como barrios, villas, asentamientos, según la forma de ocupación del suelo.

Nuestra historia se centra en Rawson, departamento ubicado a $7 \mathrm{~km}$ de la ciudad de San Juan, este distrito es uno de los más poblados de la provincia. Cuenta con una villa cabecera, asiento de las autoridades cuyo origen se remonta a 1913, en ese año un hijo de alemanes Domingo Krause fundó una aldea que llamó Augusto Krause (en honor a su padre), que con el devenir de los años paso a ser conocida como Villa Krause.

Entre 1976 y 1983 la Argentina vivió la más cruda dictadura militar de los últimos años, que generó numerosos desparecidos y exiliados. Dentro de este sombrío panorama general, florecían de todos modos la literatura, el teatro, la música y la religiosidad popular como una suerte de coartada de la realidad cruel y triste. Fue en este tiempo en que la participación del laico cobró importancia y logró insertase activamente en la iglesia ocupando el espacio que el clero dejaba. Esta situación se vivió en Villa Krause, en la Parroquia de Nuestra Señora del Rosario de Andacollo, patrona del departamento, que experimentó la gestación de una nueva primavera religiosa que abarcó los distintos sectores, desde los niños pasando por los jóvenes y llegando a los adultos. Este fenómeno religioso sobresalió en la región y llego a tener relevancia nacional expandiéndose a otras comunidades locales.

Cabe destacar la importancia que tuvo en Rawson, la inmigración, en un primer momento italiana y luego española. En este marco se destaca la figura de un joven sacerdote, nacido en Nerja (España), que había llegado a la Argentina siendo un adolescente, Francisco Martin, "Paquito" como le decía la gente, que fue quien impulsó esta primavera religiosa en momentos en que todo estaba prohibido.

Hoy a casi cuarenta años, todavía esta parte de la historia está oculta, es por eso que queremos transponer las barreras del tiempo para poder encontrar respuestas más concretas a las grandes inquietudes del presente sobre aquellos años y la religiosidad de nuestro pueblo. La existencia de numerosas fuentes ha posibilitado el aporte que hacemos, 
esto ha permitido reconstruir el suceder histórico que se vivió en estos años siendo este trabajo el inicio de futuras investigaciones.

\section{SAN JUAN LUEGO DEL CONCILIO VATICANO II}

El concilio convocado por Juan XXIII y culminado por Pablo VI, no dejó de hacerse sentir en nuestro pueblo sanjuanino. El entonces Arzobispo de San Juan, Idelfonso María Sansierra, frenó el auge renovador que caracterizó los años posteriores al Vaticano II y que querían cambiar todo. Esto provocó que un gran número de sacerdotes dejaran sus hábitos, el año 1972 se conoció como el año de los 27, ya que fue este el total de clérigos que se secularizaron: "San Juan quedó constituida en una diócesis con sacerdotes de edad superior a los cincuenta años"

Por esta causa en este periodo de tiempo no se crearon nuevas parroquias. Pero no fue impedimento para dejar de trabajar y se acentuó la religiosidad popular. El ejemplo más claro fue el surgimiento de las capillas barriales, en donde el laico donaba la imagen de algún Santo o Virgen, construyendo un pequeño templo con materiales precarios (adobe y caña en muchos casos) ubicándola en el domicilio de algún vecino, comenzando a rezarle la novena e invitando al sacerdote del lugar a participar. Estas capillas barriales con el tiempo comenzaron evolucionar siendo en épocas posteriores el origen de las actuales parroquias.

Fue un periodo de hondo enriquecimiento del laicado. Se hizo notable la participación que tuvieron los jóvenes: "El laicado se comenzó a organizar en numerosos movimientos entre las cuales la juventud tuvo un lugar destacadísimo"2. Por iniciativa de ellos se comenzaron a reorganizar nuevamente las instituciones religiosas como la Acción Católica (1975) y también fue para estos años (1974) que cobró significación la tradicional peregrinación al Villicúm, (hoy vigente) que reunió a personas de todas las edades, pero principalmente jóvenes y adolescentes que marchaban año tras año a este cerro ubicado en las afueras de la capital de San Juan:

"La organización de la misma corrió por manos de la Pastoral Juvenil, organismo creado con el fin de preparar actividades religiosas que fueran atractivas para los jóvenes. La fecha elegida siempre fue el segundo domingo de septiembre

\footnotetext{
${ }^{1}$ MORENO, Carlos Mario: Los críticos años posconciliares vistos a través de la vida de Monseñor Sansierra. San Juan, U.N.S.J. F.F.H.A. IHRAHDA, 1997, p. 24.

2 MONTES, Francisco: “La Feligresía Organizada”,_Diario de Cuyo, no 14.946 (abril de 1987), p. 13.
} 
comenzando a la 7:30 hs. con la concentración en la puerta de la Iglesia Catedral y culminando a la 17 hs. con la llegada al Villicúm”3.

Fue un evento convocante de la ciudadanía sanjuanina en donde muchos participaron con un fin religioso, pero otros lo hacían con el afán de aventura que caracterizaba a los jóvenes. Se alentó el funcionamiento de organizaciones laicas como los cursillos de cristiandad y Mallin. Durante el Gobierno de Sansierra se formaron los Círculos de Juventud ${ }^{4}$.

En el final de la década del setenta se produjo el resurgimiento de las vocaciones y quizás el broche de oro lo puso la inauguración de la Catedral el 16 diciembre de 1979: "Fue una época de gran auge vocacional, en la que afloraron muchas vocaciones y esto permitió en los años posteriores la multiplicación de parroquias y de centros de alfabetización cristiana, en las zonas urbanas como así también en el ámbito rural" ${ }^{5}$.

El comienzo de la década de los ochenta se la vio como una etapa de notables frutos en la religiosidad del pueblo sanjuanino. El laico comprometido no solo fue propagador de la doctrina, sino que se hizo sentir en la vida política y social. Esta etapa coincide con la tarea pastoral del nuevo obispo de la diócesis. Monseñor Di Stefano, que para muchos fue un referente de la participación eclesial en los principales problemas que afectaron al hombre: 'En los 80' el discurso del Obispo estuvo dirigido hacia el tecnicismo deshumanizado de los modelos económicos, en los 90’ se planteo una guerra discursiva contra la flexibilización laboral"’.

La llegada de la democracia encontró un laicado medianamente organizado con una fuerte presencia en el medio, prueba de esto fue su participación activa en el Congreso Eucarístico de 1984. Esto demostraba la actividad y el empuje de las instituciones religiosas, pero también levemente se producía el recambio generacional, paulatinamente los fieles que habían sido los promotores del cambio durante la dictadura, se alejaban y se vislumbraban ciertas brechas y roces entre muchos movimientos laicales y el clero que con el tiempo se acentuaron.

Fue precisamente desde finales de 1987 en que comienza a mostrarse una crisis notable, el desgranamiento del laicado se produce con fuerza y el distanciamiento entre la jerarquía y los laicos cobra importancia. El florecimiento religioso de años anteriores

\footnotetext{
${ }^{3}$ MORENO, Carlos Mario y otros: Memorias de un Siglo. Una Mirada significativa al siglo XX sanjuanino, U.N.S.J. F.F.H.A, Instituto de Historia Regional y Argentina Héctor D. Arias, 2003, p. 144.

4 MONTES, Francisco: "Trazos Históricos de la Arquidiócesis de San Juan de Cuyo", Diario de Cuyo, no 14.946 (abril de 1987), p. 12.

5 "Falleció Monseñor Di Stefano", en_Diario de Cuyo, no 20.176 (octubre de 2002.) p. 1.

${ }^{6}$ Ibidem, p. 3.
} 
comienza a decaer dando por terminado un tiempo que muchos recuerdan como una verdadera primavera de la Iglesia en nuestra tierra sanjuanina, en momentos en que los militares ejercían su más dura presión.

\section{LA PRIMAVERA RELIGIOSA EN RAWSON}

El departamento Rawson, ubicado a cuatro kilómetros de la ciudad de San Juan experimentó a mediados de los años setenta una auténtica eclosión religiosa que se recuerda hasta la actualidad. Este departamento poseía para el momento estudiado cincuenta y siete mil doscientos treinta y cinco habitantes según el censo de 1970 y para 1980 setenta y seis mil cuarenta y seis habitantes.

La cabecera de este departamento es Villa Krause, una ciudad ubicada en el centro sur de la Provincia de San Juan, al sur de la ciudad de San Juan, con la que posee un continuo urbano formando parte del aglomerado del Gran San Juan. Es la ciudad cabecera y asiento de autoridades gubernamentales del departamento Rawson, siendo la segunda ciudad más importante del Gran San Juan.

Posee una intensa actividad comercial, bancaria y administrativa. Allí se encuentra la Parroquia de Nuestra Señora del Rosario de Andacollo que fue para la década de mil novecientos setenta (1970) y mil novecientos ochenta (1980) un verdadero centro aglutinador de inquietudes religiosas de la zona.

Cabe aclarar que la devoción a la Virgen de Andacollo se manifiesta mediante el baile, esto es según la tradición indígena chilena que hasta el día de hoy se conserva y quienes le bailan se organizan en agrupaciones de danzantes que son conocidos como los "Chinos de la Virgen"

\subsection{Los orígenes de la comunidad parroquial}

La comunidad parroquial tuvo su origen en torno a la Virgen de Andacollo, (devoción de origen chilena llegada a San Juan desde la Serena, Chile, a principios del siglo XX) que comenzó como un culto familiar traído por los vecinos que fue cobrando significación a lo largo de los años.

Corría el año 1926, Villa Krause era un pueblo sencillo que contaba con un terreno donado por el Ing. Domingo Krause destinado a levantar una capilla. Para llevar a cabo su tarea el Padre Montes Revilla, párroco del pueblo vecino, convocó a los vecinos de 
Villa Krause a una reunión el día 24 de septiembre de 1926 en casa del señor Cecilio Gizzi. Allí se dispuso que la novena fuera en honor a la Santísima Virgen del Rosario de Andacollo, quién luego sería la patrona de la Capilla no contando con imagen, el Sr. Hilario Ríos vecino del lugar y un gran devoto de esta advocación proporcionó un cuadro de la Virgen de Andacollo. La primera novena se realizó del 10 al 19 de octubre del mismo año 1926. En 1929 se trajo desde Chile la imagen de la Virgen de Andacollo donada por una vecina del lugar: "Y el día anhelado llegó, el 22 de diciembre de 1929 a la 17 hs. el Señor Obispo Diocesano Monseñor José Américo Orzali bendijo con toda solemnidad la Capilla y la flamante imagen que hoy día se venera"7.

El 15 de enero de 1944 se produjo un terremoto con efectos devastadores, la capilla se derrumbó y la imagen comenzó a transitar distintos lugares hasta que logró su asiento en el antiguo terreno de la capilla derruida, construyendo un casilla de emergencia que sirvió de templo por muchos años.

El sismo de 1944 produjo un notable movimiento migratorio hacia Rawson, surgiendo nuevos barrios y poblados, esto llevó a que se hiciera necesaria la atención de los nuevos vecinos. Por esto el 30 de abril de 1948 el entonces Arzobispo de San Juan Mons. Dr. Audino Rodríguez y Olmos creó por Decreto la Nueva Parroquia poniendo como titular a Nuestra Señora del Rosario de Andacollo, desmembrando territorio a las antiguas parroquias de la Santísima Trinidad y Santa Bárbara de Pocito.

En agosto de ese mismo año tomó posesión el párroco Pbro. Eliseo González, como no había casa parroquial debió hospedarse en la Casa de la Obrera, que atendían las Hermanas Rosarinas, en Capitán Lazo. Breve fue la actuación del flamante párroco, ya que el 10 de abril de 1950, le sucedió el Pbro. Fernando Martínez.

El 21 de abril de 1951 se hizo cargo de la Parroquia el Pbro. Carlos Cruvellier, a él se debe la construcción de la casa parroquia, el colegio primario Mons. Juan Marcos Zapata, escuela Complementaria, (ésta última dejó de funcionar) y el Batallón de Exploradores Fray Luís Beltrán, donde se formaban los jóvenes como buenos cristianos y buenos ciudadanos. Revitalizó la Congregación Hijas de María, Apostolado de la Oración, se fundó el Centro Juventud Obrera Católica y también las cuatro ramas de la Acción Católica.

En 1967 le sucedió el Pbro. Anselmo Navas quien concluyó el templo, que llevaba tantos años en construcción: "El día 2 de agosto de 1970, el Sr. Arzobispo Mons. Dr. Ildefonso María Sansierra, bendice el anhelado Templo de la Santísima Virgen, ese día se

7 MORENO FABARO, Carlos: Bodas de diamante 1930-2005. San Juan, Parroquia de Nuestra Señora de Andacollo de Villa Krause, 2005, p. 4. 
realiza una procesión alrededor de la plaza departamental y la Imagen Milagrosa ya entra en su nueva casa, aún sin piso, altares, revoques, ni cielo raso, humilde pero ya definitivo. La devoción a la Virgen de Andacollo fue cada vez más grande"

El 25 de diciembre de 1972, Arzobispo Monseñor Idelfonso María Sansierra puso en posesión de la Parroquia al Pbro. Francisco Martín quien estuvo al frente de la comunidad hasta el 19 de febrero del año 2004. Fue bajo su gestión comenzó a gestarse una verdadera transformación de la vida religiosa del lugar que luego se expandió a otros lugares de San Juan.

\subsection{El resurgimiento religioso, de la mano de un inmigrante español}

La comunidad había pasado por numerosos avatares, la destrucción del templo en 1944, desencuentros entre la comunidad y el clero, como así también la crisis después del concilio, que llevó a que el Padre Navas, párroco del lugar, dejara los hábitos para volver a la vida secular. Todo esto fue provocando notable malestar en los fieles. El panorama era bastante desolador a comienzos de los años setenta y se veían pocas posibilidades de revertir la situación.

En 1972 asumió un nuevo sacerdote el Padre Francisco Martín hijo de inmigrantes españoles, seminarista de esta parroquia, vecino del lugar que comenzó a tratar de mejorar la situación de la comunidad. Este sacerdote había llegado a San Juan cuando tenía 11 años, vendió pan y tortitas junto con su padre para poder estudiar en la escuela primaria: "Sé lo que es dormir sin mantas, abrigándome con ladrillos calientes envuelto en trapos"

Nacido en Nerja de una familia humilde, hijo de un panadero y pescador, había sido monaguillo cuando tenía 9 años. La guerra civil lo llevó a emigrar a la Argentina, junto a sus dos hermanos. En estas tierras pudo completar sus estudios, y con 13 años ingreso al seminario de Córdoba donde cursó sus estudio eclesiásticos. En 1969 fue ordenado sacerdote y nombrado párroco de Angaco, localidad rural de las afueras de San Juan.

Frente a la crisis religiosa que vivía Rawson el obispo de turno Monseñor Sansierra, decidió nombrarlo, a "Paquito" como párroco del lugar. Para poder conectarse con la gente que estaba sumamente descreída de la iglesia, utilizó varios recursos, todos relacionados con las manifestaciones populares como el baile, la música y el deporte. Esto

\footnotetext{
${ }^{8}$ Ibidem, p.6

9 MARTIN MARTIN, Francisco: "Entre la villa y el altar", Diario de Cuyo, no 30.978 (septiembre de 2008), p. 9 .
} 
le dio buen resultado por que les mostró un Jesús divertido y desechó la idea de que la religión es distante y aburrida.

Por muchos años se consideró que el renacer religioso de esta localidad fue fruto del Padre Francisco Martín. Con el correr de los años podemos afirmar que fue un fenómeno general que obedeció a múltiples causas, una fue la actitud de apertura de parte del nuevo párroco, pero también hay que destacar el notable número de jóvenes estudiantes que vieron en la parroquia un espacio para el desarrollo de su libertad, (la parroquia era el lugar donde podían hacer muchas cosas que en la calle no podía), la presencia de laicos comprometidos como fue el caso de Otilio Barrios, hombre de la comunidad que llevaba el despacho parroquial y coordinaba casi toda la actividad pastoral de la comunidad, conocía cada familia que integraba la parroquia; así también la presencia de hombres y mujeres de más de cuarenta años que habían vivido el florecer religioso de los años cuarenta y cincuenta en San Juan y que habían militado en las filas de la Acción Católica y vieron el momento oportuno para reorganizar las instituciones laicales.

\section{La primavera religiosa}

Estos elementos llevaron a que se produjera entre 1977 y 1984 una verdadera primavera religiosa en esta parroquia que se extendió a las zonas aledañas y que sobresalió por sobre las otras comunidades de nuestra provincia y que hasta el día de hoy se recuerda.

1977 fue un año en que se observó un notable cambio en la actividad religiosa de esta comunidad y que se destacó por el resurgir del los movimientos laicales. Se reagrupó el Apostolado de la Oración, se incorporó a gente del movimiento de Cursillos de Cristiandad, se formó un grupo de catequistas debidamente preparadas y capacitadas, se revitalizó la Juventud Obrera Católica, se formó y legalizó un grupo de Jóvenes de Acción Católica, Liga de Madres de Familia, Asociación de Mujeres de Acción Católica, se creó la asociación Amigos de la Parroquia de Villa Krause (APV) que tenía como fin remodelar el templo:

"En los años setenta y primeros años de los ochenta se notó un afluente de gente que comenzó a integrarse a las nuevas instituciones laicales así es como para 1980 existían en nuestra parroquia la Liga de Madres, la Acción Católica con todas sus ramas, una catequesis debidamente organizada, el Apostolado de la Oración, La Legión de María, luego se crearan los Exploradores de la Virgen de Andacollo y 
también serán de mucha relevancia los grupos de personas que se dedicaron a colaborar materialmente con la parroquia" ${ }^{\prime 10}$.

Entre 1973 y 1977 habilitaron diez centros catequísticos en los barrios y villas más apartados dentro del área de la parroquia, que en 1977 prepararon quinientos sesenta chicos de los cuales quinientos cuarenta y seis (546) tomaron la primera comunión en el Club Unión de Rawson, la misa fue presidida por Monseñor Idelfonso María Sansierra. Todos los sábados brindaron charlas Bautismales, realizaron misiones apostólicas en las Villas San Damián, San Patricio, San Ricardo, Barboza, San Miguel, Hipódromo, Cenobia Bustos, Las Mercedes, Guzmán, Las Vicentinas, la Superiora, Las Rosas, Nacusi, Barrio Rawson y Belgrano.

Se organizaron charlas de evangelización, funciones de títeres para niños, almuerzos comunitarios en el patio de la parroquia, y en el camping del Club Sirio Libanés que era uno de los más extensos y amplios del lugar. En junio del año 1977 se comenzó a celebrar los días domingos la misa de 11 de la mañana con el fin de que los niños que se preparaban en la catequesis tuvieran vida litúrgica.

Los jóvenes organizaron la peregrinación Juvenil al Camping de Asociación de Trabajadores de la Salud ubicado en calle 11 y Costa Canal esto es a seis kilómetros de Villa Krause, contaron con más de cuatrocientos caminantes, sin contar los adultos, padres de los participantes que esperaban en el lugar, Esta peregrinación se llevó a cabo hasta 1988 año en que perdió convocatoria.

La memoria confeccionada a principios de 1978 decía lo siguiente:

"En estos últimos años se está realizando en nuestra parroquia una gran campaña de Catequesis en todas las villas y barrios pertenecientes a la jurisdicción parroquial y que son más de 80 , ello se debe al gran espíritu evangélico del actual párroco, cuya labor tesonera nos contagia y alienta para trabajar por nuestra Parroquia, nosotros sus feligreses, laicos comprometidos hagamos el firme propósito de trabajar siempre unidos a él por el bien de todos nuestros hermanos, todos somos Iglesia, el pueblo predilecto de Dios, somos una gran familia"11.

Es muy interesante observar el tono triunfalista que posee esta publicación y que fue repartida en una cena de gala con el fin de festejar los logros alcanzados. Resalta la idea de que la parroquia es una familia, unida al sacerdote, aspectos que tenían notable

\footnotetext{
${ }^{10}$ MORENO FABARO, Carlos, Bodas de Diamantes..., op. cit., p. 15.

${ }^{11}$ PARROQUIA NUESTRA SEÑORA DE ANDACOLLO DE VILLA KRAUSE: Memoria de lo realizado entre diciembre 1973- enero de 1978. San Juan, 1978), p. 1.
} 
significación para la época, ya que se presentaba la estabilidad, el trabajo, la comunidad como frutos que brotaban de la vinculación con la jerarquía.

Con el fin de crear un clima festivo en la comunidad desde 1973 se estableció como fecha para celebrar a la Virgen de Andacollo el segundo domingo de enero, logrando de esta manera que las fiestas de fin de año se extendieran y que en la mente de la gente del lugar se comenzara a preparar la Navidad, el Año Nuevo, los Reyes y la Fiesta de la Virgen.

Con la Festividad de la Virgen de Andacollo se daba por finalizado el tiempo de Navidad y se sacaban los adornos propios de esta fecha. De esta manera Rawson pasó a tener cuatro fiestas de fin de año, haciéndose costumbre en los vecinos del lugar y luego en todo San Juan

La fiesta tomo características populares y logró superar otras festividades del departamento, se comenzaron a organizar eventos musicales, ranchos típicos que llevó a que mucha gente de los alrededores a participará de los festejos.

"A las celebraciones de las cuatro barriadas que circundan nuestra capital Concepción, Santa Lucia, Desamparados y Trinidad paulatinamente se le fueron agregando otras en las últimas décadas que compiten en brillo y concurrencia tales como Santa Bárbara de Pocito Andacollo de Villa Krause, Albardon, Cristo Rey entre otras" $"$.

La fiesta patronal de 1978 contó con una notable concurrencia de gente, más de dos mil confesiones, como así también el número de comuniones que llegó a las tres mil quinientas y unas dieciséis mil personas en la procesión. Para las fiestas patronales resultó pequeña la Iglesia, siendo numerosa la cantidad de niños que reciben por primera vez la Eucaristía, esta ceremonia se llevó a cabo en las Instalaciones del Club Unión de esta villa.

También fueron muchas las personas entre adultos y niños que recibieron el Sacramento de la Confirmación, que se organizó en dos tandas, una vez en la noche del penúltimo día de la novena para adultos de más de catorce años y el día de la festividad patronal para los niños que recibieron la primera comunión.

En 1978 el número de niños que recibían la comunión llego a cuatrocientos, en 1979 a novecientos y en 1983 a setecientos niños. Como así también el número de fieles que participaban de la procesión nunca bajó de diez mil personas: "Fue la época de las primeras comuniones monumentales que se celebraban en el Club Unión de Rawson, por la notable cantidad de niños que recibían este sacramento. Visitó por aquel entonces, enero

${ }^{12}$ MONTES, Francisco: “Trazos...”, op. cit., p. 16. 
de 1981, el flamante obispo Monseñor Italo Severino Distefano que llegaba por primera vez a tierra sanjuanina para celebrar la misa de primeras comuniones"13.

Fue también en estos años en que comenzaron a llegar distintas agrupaciones de danzantes que venían de Chimbas, Marquesado, Albardón a bailarle a la Virgen.

Pero la devoción a la Virgen fue acompañada por numerosas prácticas. En los primeros tiempos era común que se le pusiera en la capa dinero pegado con alfileres, con el tiempo esta práctica se dejó de hacer, pero se le comenzaron a hacer nudos en cintas que eran colocadas para este fin en la mano de la imagen, al parecer esta práctica era de origen chileno y simbolizaba la consagración de atar sus vidas a la mano de la Virgen. El transportar la imagen en los hombros era otra forma de manifestación de la fe del pueblo.

Para 1984 se la consideraba la fiesta más grande de San Juan, fue por este motivo que se comenzaron a hacer presente personas notables, en enero de 1986 llegó el Nuncio Apostólico de su Santidad, Monseñor Ubaldo Calabresi que hacia su entrada a Villa Krause en carruaje de caballos por la calle Boulevard Sarmiento, presidió las fiestas patronales de ese año, e impartió la confirmación a numerosos niños y jóvenes. En 1987 las fiestas fueron presididas por los Obispos de la diócesis de San Luís y la Rioja Monseñor Rodolfo Laise y Monseñor Bernardo Witte.

Rawson se mostraba admirado de lo fuerte que era esta festividad, que ya tomaba formas de fiesta social superando los límites religiosos. Esto último se acentuó a finales de los 80 y durante la década del 90. Actualmente la fiesta volvió a celebrarse el 26 de diciembre o en los días próximos, haciéndola coincidir con la fiesta en Chile y buscando darle el sentido religioso que una vez tuvo.

\section{El resurgimiento juvenil}

En 1975 se comenzó organizar un coro que se iba a encargar de animar en la misa vespertina del día domingo, en la organización del mismo participaban dos jóvenes que pertenecían al Colegio Don Bosco, uno de ellos el actual Padre Manolo Fernández y el otro Emilio Pelanda, músico, también de la comunidad Salesiana. Esto no estaba fuera de lo que pedía el Episcopado Argentino que para aquellos años había planteado como opciones:

13 MORENO FABARO Carlos: "La Vecina más querida", Diario de Cuyo, no 40.543 (diciembre de 2008), p. 22. 
"Las opciones para estos años eran dos, la primera (1975-1980) Matrimonio y familia y la segunda (1980-1985) la Juventud, esta última fue una iniciativa de mediano plazo para la iglesia de Argentina bajo el lema "Toda la Iglesia evangeliza a toda la Juventud", fueron dos las tareas que se propusieron, conocer pastoralmente la realidad juvenil del país y desarrollar una evangelización que respondiese a esta realidad"14.

El hecho de comenzar a tocar la guitarra motivó a que muchos jóvenes estudiantes del lugar se acercaran y comenzaran a integrar este nuevo movimiento. Estas chicas y muchachos tuvieron la idea de formar un grupo juvenil, que se reunía antes de la misa y donde realizaban principalmente la lectura del evangelio: “...aparentemente esto abría sido en abril de 1976 y recuerdo que en la primera reunión leímos el evangelio de los discípulos de Emaus" ${ }^{\prime 15}$.

Fue el encargado de la pastoral y secretario del padre Francisco Martin, quien sugirió formar la Acción Católica, que después de mucho pensarlo aceptaron. En 1977, ya estaba oficialmente constituida: "Así por esos años funcionaba un grupo juvenil que comenzó a crecer cada vez más, debido a las buenas relaciones humanas y cristianas, de esta manera se fue formando la Acción Católica, a quienes el párroco comenzó a confiarles la Formación de la Catequesis, esto atraía a muchos jóvenes que deseaban formar parte de este trabajo"16.

Desde 1961 no había movimientos juveniles en Rawson. Los jóvenes que asumían la conducción de la pastoral juvenil experimentaron una profunda brecha generacional. Entre ellos y los dirigentes que rondan los cincuenta años, no parecía haber nadie. Las ramas juveniles de estos movimientos, comenzaron a actuar en las comisiones de jóvenes y en las organizaciones de eventos que llegaron a ser parte de la pastoral juvenil Diocesana, que comenzó a ser un lugar de eclosión tanto de la vida de los jóvenes como de las iniciativas pastorales de la iglesia local.

La atracción para pertenecer a este grupo era la figura del sacerdote, que preparaba campamentos, que jugaba al voley, al fútbol, acompañaba a los jóvenes a los lugres recreativos, camping, piletas, canchas. Otro aspecto importante era el trato de hermanos y la protección entre unos y otros, sobre todo la protección de los jóvenes varones hacia las chicas, esto daba una buena vista a los padres que generaba confianza.

\footnotetext{
14 PEREA, Sandra, Testimonio Oral. San Juan 20 de Noviembre del 2009.

15 Ibídem.

${ }^{16}$ BENAVIDEZ, María Rosa, Testimonio oral. San Juan 8 de julio de 2010.
} 
Se comenzaron a organizar eventos que movían mucha gente, una de ellas fueron las peregrinaciones, estas se hacían en octubre, y convocaba a todos los alumnos de las escuelas secundarias del departamento, se trataba un tema y se debatía mientras se caminaba, llegaban a reunir entre cuatrocientas y quinientas personas.

Otro hecho convocante fue la preparación de la cuaresma, los jóvenes se reunían para comenzar a preparar la Pasión teatralizada, que se montaba en el club Unión de Rawson, llegando a reunir tres mil personas. Todos los jóvenes participaban y era verdaderamente todo un evento para el departamento. Comenzó a realizarse en 1978 y la última vez que se puso en escena fue en 1986.

Otro aspecto importante fueron las noches heroicas, se llevaban a cabo durante las fiestas patronales, lo que permitía que se quedara mucha gente. Sin la presencia del sacerdote, pero sí de los seminaristas, quienes tenían a cargo la organización. En esas noches de oración se tocaba la guitarra, se tomaba mate, se hacían trabajos en grupo: “...en 1981 se analizaba el tema "Solo le pido a Dios" que en aquellos momento no era bien visto, en 1983 con el retorno de la democracia se canto el tema "todavía cantamos, todavía reímos", de Víctor Heredia. Participábamos todos desde niños de 11 años, hasta adultos de 50 años" $" 17$.

Los campamentos fueron también un elemento de atracción, ya constituida la Acción Católica se trabajaba todo el año para participar de este evento, eran alrededor de cien personas que por quince días se establecían en la escuela Rafael Obligado en el departamento Zonda, esto era después de la fiesta patronal, en la segunda quincena de enero, participaban niños y niñas desde los siete años y jóvenes varones y mujeres. Según la opinión del párroco esta era la mejor manera de formar matrimonios cristianos. El último de estos se realizo en enero de 1985.

En 1984, estos jóvenes dirigentes pasaron a integrar muchos de ellos el Consejo Diocesano de Acción Católica otros quedaron en la parroquia, pero para 1987 ya ninguno estaba, se comenzaba una larga crisis de participación religiosa de los jóvenes, con notables altibajos pero quienes participaron de estos años todavía recuerdan como la parroquia se había transformado en el espacio mágico que ellos anhelaban.

17 VILLAFAÑE, Juan Carlos, Testimonio oral. San Juan 21 de julio de 2010. 


\section{PALABRAS FINALES}

El Concilio Vaticano II se hizo sentir en nuestra sociedad a causa de la notable deserción de clérigos, obligando a los laicos a satisfacer por si mismos sus propias necesidades espirituales. Frente a esta situación, en el departamento Rawson se produce un notable resurgimiento religioso que se va a propagar en el resto de las comunidades de San Juan. Este renacimiento tuvo su auge entre 1977 y 1984, el eje central de este renacimiento fueron los laicos y principalmente los jóvenes que encontraron en la parroquia el lugar para el desarrollo de múltiples actividades. Con la llegada de la democracia esta primavera comenzó lentamente a marchitarse quedando en el imaginario de los que lo vivieron los momentos significativos de esta época. 